\title{
First cases of Middle East Respiratory Syndrome Coronavirus (MERS-CoV) infections in France, investigations and implications for the prevention of human-to-human transmission, France, May 2013
}

\author{
A Mailles (a.mailles@invs.sante.fr) ${ }^{1}, \mathrm{~K}$ Blanckaert ${ }^{2,3}$, P Chaud $^{2,4}$, S van der Werf 5 , B Lina ${ }^{6}$, V Caro 7 , C Campese ${ }^{1}$, B Guéry $^{8}$, \\ H Prouvost ${ }^{4}$, X Lemaire9, M C Paty ${ }^{1}$, S Haeghebaert ${ }^{4}$, D Antoine ${ }^{1}$, N Ettahar ${ }^{10}$, H Noel $^{1}$, S Behillil ${ }^{5}$, S Hendricx ${ }^{9}$, J C Manuguerra ${ }^{7}$, \\ V Enouf ${ }^{6}$, G La Ruche ${ }^{1}$, Caroline Semaille ${ }^{1}$, B Coignard $^{1}$, D Lévy-Bruhl ${ }^{1}$, F Weber $^{1}$, C Saura $^{1}$, D Che ${ }^{1}$, The investigation team ${ }^{11}$ \\ 1. Institut de veille sanitaire (InVS), Saint Maurice, France \\ 2. These authors contributed equally to this work \\ 3. Antenne Régionale de Lutte contre les Infections Nosocomiales (ARLIN), Lille, France \\ 4. Institut de Veille Sanitaire, Lille, France \\ 5. National Reference Center for influenza viruses (coordinating center) and Unit of Molecular Genetics of RNA Viruses, \\ coordinating center, Institut Pasteur, Paris, France \\ 6. National Reference Center for influenza viruses, Hospices Civils de Lyon and Virpath, Université Claude Bernard Lyon1, \\ Lyon, France \\ 7. Cellule d’Intervention Biologique d’Urgence (CIBU), Institut Pasteur, Paris, France \\ 8. Centre Hospitalier Régional et Universitaire, Université de Lille 2, Lille, France \\ 9. Centre hospitalier, Douai, France \\ 10. Centre Hospitalier, Valenciennes, France \\ 11. The members of the team are listed at the end of the article
}

Citation style for this article:

Mailles A, Blanckaert K, Chaud P, van der Werf S, Lina B, Caro V, Campese C, Guéry B, Prouvost H, Lemaire X, Paty MC, Haeghebaert S, Antoine D, Ettahar N, Noel H, Behillil S, Hendricx S, Manuguerra JC, Enouf V, La Ruche G, Semaille C, Coignard B, Lévy-Bruhl D, Weber F, Saura C, Che D, The investigation team. First cases of Middle East Respiratory Syndrome Coronavirus (MERS-CoV) infections in France, investigations and implications for the prevention of human-to-human transmission, France, May 2013. Euro Surveill. 2013;18(24): pii=20502. Available online: http://www.eurosurveillance.org/ViewArticle.aspx?Articleld=20502

In May 2013, Middle East Respiratory Syndrome Coronavirus (MERS-CoV) infection was diagnosed in an adult male in France with severe respiratory illness, who had travelled to the United Arab Emirates before symptom onset. Contact tracing identified a secondary case in a patient hospitalised in the same hospital room. No other cases of MERS-CoV infection were identified among the index case's 123 contacts, nor among 39 contacts of the secondary case, during the 10-day follow-up period.

On 7 May 2013, Middle East Respiratory syndrome-Coronavirus (MERS-CoV) infection was confirmed in France in a traveller who became ill after returning from the United Arab Emirates (index case). An investigation was immediately carried out among his contacts since onset of illness, as well as among individuals who had co-travelled with him to the United Arab Emirates. The aim of the investigation was to detect possible other cases and prevent human-to-human transmission. The secondary objective was to try to identify any likely circumstances of exposure to the virus during his travel.

MERS-CoV is a novel virus among the genus Betacoronavirus, which was initially identified in Saudi Arabia in September 2012, in two patients with severe pneumonia [1]. As of 7 May 2013, when the case in France was identified, 30 cases had been confirmed as infected with the virus worldwide, including four diagnosed in the United Kingdom (UK) and two in Germany $[2,3]$.

\section{Surveillance, contact tracing and case finding in France}

\section{French surveillance system}

In France, suspected cases of MERS-CoV infection have to be reported by attending physicians to regional health agencies and hospital infection control teams. After validation of the classification as a possible case by a French Institute for Public Health Surveillance (InVS) regional office (CIRE), located in a regional health agency, a standardised notification form including socio-demographical information, clinical details, and history of travel in at-risk countries is completed for each possible case.

Up to 17 May, a possible case was defined as follows:

(i) any patient with a history of travel in an at-risk country, who presented with clinical signs and/or imaging consistent with acute respiratory distress syndrome (ARDS) or pulmonary infection, encompassing fever $\geq 38^{\circ} \mathrm{C}$ and cough within 10 days after return;

(ii) any contact of a symptomatic possible or confirmed case, presenting with acute respiratory infection, whatever the severity, with an onset of symptoms within 10 
days of the last contact with a possible/confirmed case while symptomatic.

The list of at-risk countries, as defined in European Centre for Disease Prevention and Control (ECDC) rapid risk assessment dated 7 December 2012, included, Bahrain, Iran Iraq, Israel, Jordan, Kuwait, Lebanon, Palestine, Oman, Qatar, Saudi Arabia, Syria, United Arab Emirates, and Yemen [4].

For each possible case, respiratory samples (nasopharyngeal aspiration/swab, bronchoalveolar lavage (BAL) fluid when indicated, or induced sputum) are collected and sent to the National Reference Centres for influenza (Institut Pasteur, Paris (coordinating centre) or Hospices civils, Lyon) to be tested for the presence of MERS-CoV genome by real-time reverse transcriptase polymerase chain reaction (RT-PCR) $[5,6]$.

A confirmed case is defined as a possible case with a positive MERS-CoV RT-PCR on respiratory samples $[5,6]$.

Moreover, as part of the usual surveillance of both emerging or nosocomial infections, any cluster of hospitalised patients or healthcare workers (HCW) presenting with severe respiratory infections, regardless of any history of travel in at-risk countries, has to be notified to Public Health Authorities.

\section{Contact tracing and case finding}

The contact tracing of all identified cases is implemented as soon as the diagnosis is confirmed. Contacts are defined as all people who provided healthcare to a confirmed case without individual protection, shared the same hospital room, lived in the same household or shared any leisure or professional activity with a confirmed case since this case's onset of clinical symptoms of MERS-CoV infection (respiratory, digestive or even isolated fever $\geq 38^{\circ} \mathrm{C}$ ). All contacts are followed-up during a 10-day period (equal to the maximum incubation period according to the knowledge of the disease at the time of the investigation described in this report) after their last contact with the confirmed case to check for clinical symptoms, and asked to measure their body temperature twice a day. The follow-up consists of daily calls from the InVS or CIRE for contacts who are not HCW or from the hospital infection control teams for $\mathrm{HCW}$, to check for the occurrence of clinical symptoms and fever $\left(\geq 38^{\circ} \mathrm{C}\right)$. Contacts are also provided with a hotline number to call anytime in case of any symptom.

For confirmed cases with a history of travel in an atrisk country, a contact tracing of all members of the travel group (co-travellers) is implemented. If the confirmed case had onset of symptoms during the travel, co-travellers are investigated as contacts. Because they potentially have been exposed to the same source of infection (co-exposed), co-travellers are followedup during a 10-day period after their return from an at-risk country. They are interviewed about the nature and date of their activities, exposure to people presenting with respiratory symptoms, food consumption and exposures to animals, and to aerosols during the travel, in order to investigate the source of infection.

The investigations are carried out with respect to French regulations (authorisation of the Commission Nationale Informatique et Libertés $n^{\circ} 341194 V 42$ ).

\section{Detected confirmed cases}

The index case was a 64 year-old male patient with a history of renal transplant, who had returned from the United Arab Emirates on 17 April. He had onset of symptoms on 22 April consisting of fever $\left(38.9^{\circ} \mathrm{C}\right)$ and diarrhoea but no respiratory signs. He was admitted in hospital A on 23 April where he was hospitalised until 29 April. On 26 April, the patient presented with dyspnoea and cough; he was transferred to hospital B for a single calendar day to undergo a BAL in a specialised respiratory unit and was re-admitted in hospital A. On 29 April, he was transferred to hospital C in an intensive care unit (ICU). All hospitals were in the same department, whereby hospitals $A$ and $B$ were in the same town, while $C$ and $D$ were in two other towns. Possible MERS-CoV infection was suspected on 1 May and the index case was isolated and individual precautions implemented for HCW and visitors. MERSCoV infection was confirmed on 7 May. On 8 May, the index case was transferred to hospital $D$ where he was admitted in ICU in a specialised unit with maximal precautions, including a negative pressure room. He died on 28 May 2013, 36 days after onset of symptoms.

Case 2 was identified during the contact tracing of the index case. He was a 51-year-old male patient treated with steroids for several months prior to hospitalisation. He had no history of travel during the weeks before his hospitalisation. He shared with the index case a $20 \mathrm{~m}^{2}$ room with a single bathroom in hospital A from 26 to 29 April, while the index case presented with respiratory symptoms (Figure). The beds in the room were $1.5 \mathrm{~m}$ apart [7]. He was discharged on 30 April. Onset of symptoms suggestive of MERS-CoV infection occurred on 8 May, 12 days after first exposure. He first presented with malaise, muscle pain and fever $\left(38.5^{\circ} \mathrm{C}\right)$ in the afternoon, and cough later that day. As case 2 was known as a contact of the index case, he was admitted in the infectious diseases ward in hospital $D$ and isolated on 9 May. MERS-CoV infection was confirmed during the night of 11 to 12 May. Case 2 was admitted in ICU on 12 May where he is still isolated with the same precautions as the index case.

\section{Contact tracing}

The index case had travelled in the United Arab Emirates from 9 to 17 April 2013 with 37 co-travellers and his spouse. All co-travellers were interviewed from 10 to 13 May, and none had had any respiratory or digestive symptoms or fever, neither during the journey nor since their return. Except for the spouse, 
Timeline of epidemiological features of two cases of Middle East Respiratory Syndrome Coronavirus (MERS-CoV) infection and exposure and follow-up period of their contacts ( $n=162)$, France, April-May 2013

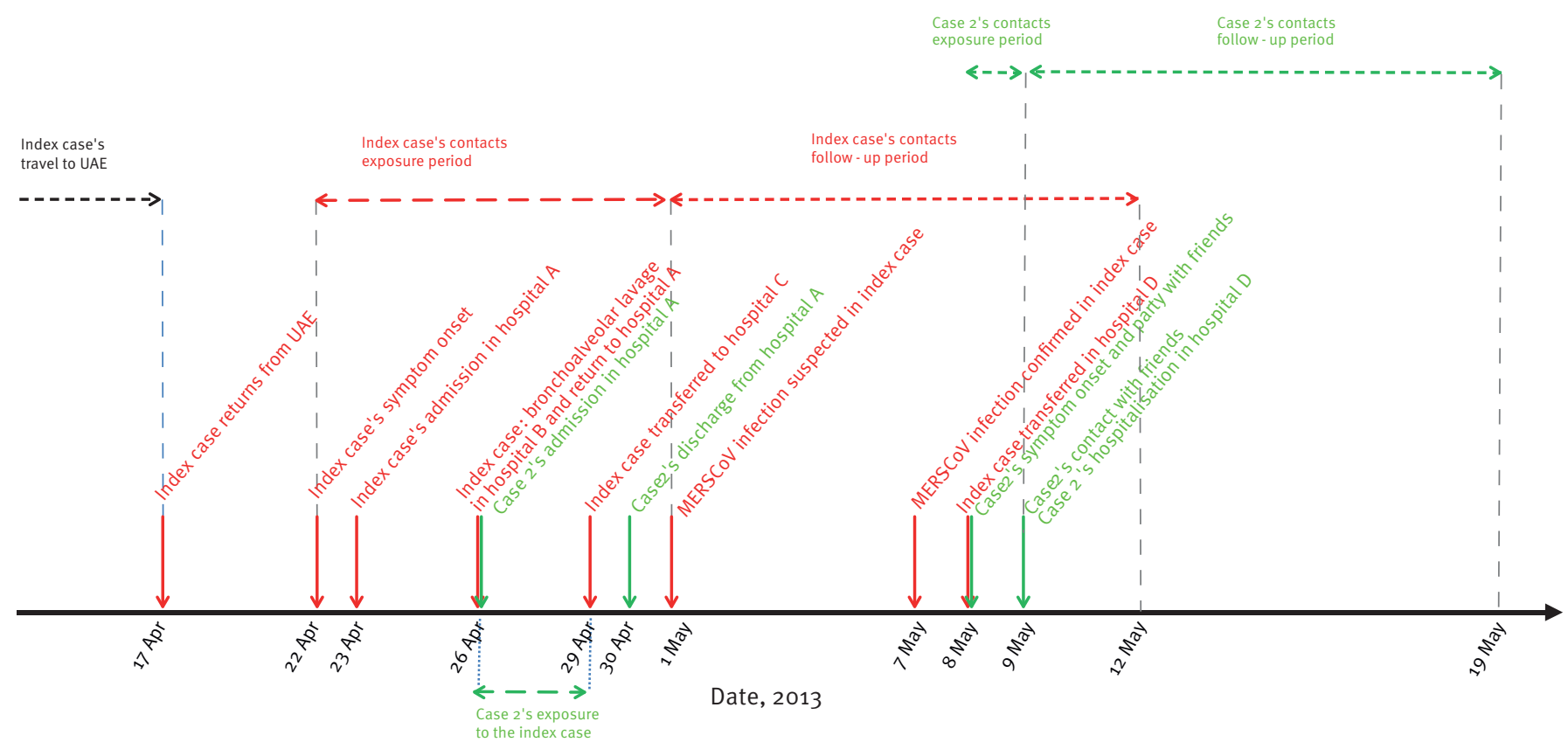

MERS-CoV: Middle East respiratory syndrome-Corona-Virus; UAE: United Arab Emirates.

as their interview took place 23 to 26 days after their last contact with the at the time asymptomatic index case, they were not followed-up. All had done the same itinerary and shared common activities with the index case. Their interview did not allow suggesting any hypothesis about the source of infection.

In total, 123 contacts exposed to the index case from his onset of symptoms (22 April) until his isolation (1 May) were identified and interviewed from 8 to 10 May. Six of them were family members who visited the index case in hospital A. Other contacts were $88 \mathrm{HCW}$ and two patients (including case 2) in hospital A, four HCW in hospital B, $20 \mathrm{HCW}$ and three patients in hospital C. Of the five contacts who were patients, only case 2 had shared a room with the index case. No contacts were identified in hospital D, as maximal infection control precautions had been immediately taken. Seven of the total 123 contacts matched the case definition for possible cases and were therefore tested for MERS-CoV infection (samples were taken between one and six days after contacts became symptomatic): only case 2 tested positive.

In total, 39 people were identified as contacts of case 2: 30 had attended a party with case 2 on 8 May, two had visited him at home on 9 May before admission to hospital $D$, and seven had visited him at home on 9 May and attended the party. Among those 39, 16 had a face-to-face conversation longer than 15 minutes with case 2 and were considered close contacts as described elsewhere [3]. All 39 contacts were interviewed on 12 May, and followed-up until 19 May for those with last contact on 9 May $(n=9)$, and until 18 May for others $(n=30)$. As of 19 May, all were asymptomatic.

\section{Control measures}

As soon a MERS-CoV infection was confirmed, the index case and case 2 were isolated, using airborne and contact precautions, in a negative pressure room with dedicated staff [8]. Case 2 had to wear a surgical mask until his medical condition required mechanical ventilation, and HCW who took care of the patients had to wear a filtering face piece (FFP)2 mask [8].

Close contacts of case 2 were asked not to return to work or school until the end of the follow-up, and were provided with surgical masks to wear when not alone and alcohol based hand rub. Other contacts could go on with their usual activities but had to carry a mask, and in case of symptoms, wear it and immediately go back home and call the dedicated hotline [8]. Particular measures for close contacts were implemented after case 2 was diagnosed, and were therefore not applied to contacts of the index case. 
Both confirmed cases were notified to the ECDC and the World Health Organization (WHO), respectively on 8 May and 12 May.

Information about the disease and the outbreak was released to the public through the media, and to travellers via flyers and posters disseminated in airports. Specific information about the patients' management was disseminated to healthcare professionals through mailing lists and institutions' websites.

\section{Discussion and conclusion}

We report the investigation of the first two cases of MERS-CoV diagnosed in France since the emergence of the virus was first described in Saudi Arabia in 2012 [1]. The index case diagnosed in France was imported from the United Arab Emirates, and the second case resulted from a nosocomial infection. Considering that both cases spent four days (26 to 29 April) in the same hospital room, the incubation period of case 2 ranged from nine to 12 days. This emphasises the need for gathering more clinical information from future and past cases to be able to determine precisely the incubation period.

As of 7 June 2013, 55 cases were identified worldwide since the beginning of the worldwide outbreak [9], suggesting a limited human-to-human transmission, even if we assume that some cases may have not been diagnosed.

The index case was initially admitted with an atypical presentation consisting of digestive symptoms but no respiratory signs. Therefore, MERS-CoV infection was not suspected until the patient was in ICU with severe pneumonia. This finding raised the importance of disseminating information about emerging diseases in all hospital settings, including those wards that are not specialised in infectious diseases or critical care.

In-hospital transmission has previously been described in England, in a family member who visited a confirmed case in hospital [10]. A hospital cluster suggestive of nosocomial transmission has also been reported in Saudi Arabia, although the details of the transmission are still under investigation [11]. In France, a secondary infection was diagnosed in another hospitalised patient with underlying condition and long-term steroid treatment. The respiratory presentation of the index case strongly suggests an airborne transmission in the hospital room shared by both patients. However, some questions remain about the possible infectiousness of other body fluids or clinical samples, including stools as the index case presented with diarrhoea at an early stage of his disease, and a cross transmission through contaminated surfaces, medical devices or hands of HCW cannot be ruled out. During the severe acute respiratory syndrome (SARS) outbreak in 2003, a cluster of infections was detected in inhabitants of the same building. Virus aerosols originating from a flat where the index case of the cluster had had digestive symptoms, spread by drainage pipes, were assumed to be the origin of the infection of other cases in the cluster [12].

The large majority of reported MERS-CoV cases worldwide had underlying conditions and presented with severe respiratory infection requiring hospitalisation in ICU. Atypical presentations in immunocompromised patients may be really challenging for clinicians, especially as digestive symptoms are very common in travellers. Based on the index case's clinical presentation and on knowledge acquired from the SARS outbreak [13], the French case definition for possible cases was extended on 17 May to improve the sensitivity of the surveillance system. It now includes severe febrile clinical signs or febrile diarrhoea in immunocompromised persons or in those with chronic underlying conditions, returning from an at-risk country [14].

Despite the identification of few infections since 2012, MERS-CoV has demonstrated a real potential for nosocomial transmission, and stringent recommendations have to be implemented around possible cases as soon as MERS-CoV infection is suspected. The challenge presented by possible atypical presentations highlights the need for a better knowledge about both the virus and the disease.

Useful knowledge about the infection by MERS-CoV might be obtained from serological investigation in people who shared exposures of confirmed cases, or in contacts of confirmed cases. Such studies might help raising hypothesis about the extent of transmission and risk factors for infection and fatal outcome and must be encouraged.

\section{Acknowledgements}

David Briand, Mathilde Benassaya, Marie Lazzerini, and Clio Socratous of the National Reference Centre for influenza viruses (Institut Pasteur) contributed to the diagnosis of cases. The authors are grateful to all clinicians and biologists who contribute to the surveillance of this emerging infection.

\section{Investigation team}

InVS, Saint Maurice, France: Sandrine Barquin, Fatima Belghiti, Alexandre Blake, Gabriel Bedubourg, Isabelle Bonmarin, Jérémie Carré, Carole Debreyer, Gilles Delmas, Anne Gallay, Claire Gourier-Fréry, Etienne Lucas, Roselyne Pinget, Mathieu Tourdjmann, Sarah Tubiana, Dieter Van Cauteren, Annie Velter, Manuel Zubaran.

InVS, Lille, France: Audrey Andrieu, Emile Baro, Guillaume Clement.

National Reference Center for influenza viruses, Hospices Civils de Lyon and Virpath, Université Claude Bernard Lyon1, Lyon, France: Maude Bouscambert, Martine Valette.

Centre Hospitalier Régional et Universitaire, Université de Lille 2, Lille, France: Karine Faure, Hugues Melliez, Fanny Vuotto.

Centre hospitalier, Douai, France: Loubna El-Mansouf.

Centre hospitalier, Valenciennes, France: Anne-Adélaide Cracco. 
Regional Health Agency, Lille, France: Jean-Philippe Legendre, Sandrine Segovia-Kueny.

Centre hospitalier universitaire, Tourcoing, France: Eric Senneville.

\section{Conflict of interest}

None declared.

\section{Authors' contributions}

Alexandra Mailles: wrote the manuscript. Alexandra Mailles, Christine Campese, coordinated the investigation of cotravellers of the index case. Pascal Chaud, Marie-Claire Paty, Caroline Semaille: coordinated the investigations of confirmed cases. Karine Blanckaert, Sylvie Hendricx: contact tracing and follow-up of healthcare workers. Pascal Chaud, Sylvie Haeghebaert: coordinated the contact tracing for index case and follow-up of healthcare workers and family contacts of the index case. Sylvie van der Werf, Bruno Lina, Valérie Caro, Sylvie Behillil, Jean-Claude Manuguerra, Vincent Enouf: implemented the biological diagnosis in France and carried out the diagnosis of all possible cases, including both confirmed case. Benoit Guéry, Xavier Lemaire, Nicolas Ettahar: clinical management of confirmed cases and symptomatic contacts. Delphine Antoine, Harold Noel, Guy La Ruche, Pascal Chaud, Hélène Prouvost coordinated the contact tracing and follow-up of contacts of case. Didier Che, Bruno Coignard, Daniel Levy-Bruh: expertise in risk assessment. Bruno Coignard, Daniel Levy-Bruhl, Françoise Weber: supervised the investigations and coordinated the relationship with health authorities in France and Europe. Christine Saura, Didier Che: implemented the surveillance system in France and coordinated all involved partners since September 2012. All: revised the manuscript and contributed with specific comments.

\section{References}

1. Zaki AM, van Boheemen S, Bestebroer TM, Osterhaus AD, Fouchier RA. Isolation of a novel coronavirus from a man with pneumonia in Saudi Arabia. N Engl J Med. 2012;367(19):181420.

http://dx.doi.org/10.1056/NEJMoa1211721

2. Buchholz U, Müller MA, Nitsche A, Sanewski A, Wevering N, Bauer-Balci T, et al. Contact investigation of a case of human novel coronavirus infection treated in a German hospital, October-November 2012. Euro Surveill. 2013;18(8): pii=20406. Available from: http://www.eurosurveillance.org/ViewArticle. aspx?Articleld $=20406$

PMid:23449231

3. Bermingham A, Chand MA, Brown CS, Aarons E, Tong C, Langrish C,et al. Severe respiratory illness caused by a novel coronavirus, in a patient transferred to the United Kingdom from the Middle East, September 2012. Euro Surveill. 2012;17(40):pii=20290. Available from: http://www. eurosurveillance. org/ViewArticle. aspx?Articleld=20290

4. European Centre for Disease Prevention and Control (ECDC). Update: Severe respiratory disease associated with a novel coronavirus. Stockholm: ECDC; 7 Dec 2012. [Accessed 10 Jun 2013]. Available from: http://www.ecdc.europa.eu/en/ publications/Publications/20121207-Novel-coronavirus-rapidrisk-assessment.pdf

5. Corman VM, Eckerle I, Bleicker T, Zaki A, Landt O, EschbachBludau M, et al. Detection of a novel human coronavirus by real-time reverse-transcription polymerase chain reaction. Euro Surveill. 2012;17(39):pii=20285. Available from: http:// www.eurosurveillance.org/ViewArticle.aspx?Articleld =20285

6. Corman VM, Müller MA, Costabel U, Timm J, Binger T, Meyer B, et al. Assays for laboratory confirmation of novel human coronavirus (hCoV-EMC) infections. Euro Surveill. 2012;17(49):pii: 20334. Available from: http://www. eurosurveillance.org/ViewArticle. aspx?Articleld =20334

7. Guery B, Poissy J, El Mansouf L, Séjourné C, Ettahar N, Lemaire $X$, et al. Clinical features and viral diagnosis of two cases of infection with Middle East Respiratory Syndrome coronavirus: a report of nosocomial transmission. Lancet. 2013 May 30. http://dx.doi.org/10.1016/S0140-6736(13)60982-4

8. Haut conseil de la santé publique (HCSP). Avis relatif à la prise en charge des patients suspects d'infections dues au nouveau coronavirus (HCoV-EMC). [Guidelines for the management of patients with suspected MERS-CoV]. Paris: HCSP; 19 Mar 2013. [Accessed 29 May 2013]. Available from: http://www.hcsp.fr/ explore.cgi/telecharger/hcspa20130319_nouveaucoronavirus. pdf

9. World Health Organization (WHO). Middle East respiratory syndrome coronavirus (MERS-CoV) - update. Geneva: WHO; 07 Jun 2013. [Accessed 11 Jun 2013]. Available from: http://www. who.int/csr/don/2013 06 07/en/index.html

10. Health Protection Agency (HPA) UK Novel Coronavirus Investigation team. Evidence of person-to-person transmission within a family cluster of novel coronavirus infections, United Kingdom, February 2013. Euro Surveill. 2013;18(11):pii=20427. Available from: http://www.eurosurveillance.org/ViewArticle. aspx?Articleld $=20427$

11. ProMED-mail. Novel Coronavirus - Eastern Mediterranean (21): Saudi Arabia. Archive Number: 20130509.1701527. 09 May 2013. [Accessed 29 May 2013]. Available from: http://www. promedmail.org/direct.php?id=20130509.1701527

12. Yu IT, Li Y, Wong TW, Tam W, Chan AT, Lee JH, et al. Evidence of airborne transmission of the severe acute respiratory syndrome virus. N Engl J Med. 2004;350(17):1731-9 http://dx.doi.org/10.1056/NEJMoa032867 PMid:15102999

13. Christian MD, Poutanen SM, Loutfy MR, Muller MP, Low DE. Severe acute respiratory syndrome. Clin Infect Dis. 2004;38(10):1420-7. http://dx.doi.org/10.1086/420743

14. European Centre for Disease Prevention and Control (ECDC) Severe respiratory disease associated with Middle East respiratory syndrome coronavirus (MERS-CoV). Stockholm: ECDC; 17 May 2013. [Accessed 29 May 2013]. Available from: http://www.ecdc.europa.eu/en/publications/Publications/riskassessment-middle-east-respiratory-syndrome-coronavirusMERS-CoV-17-may-2013.pdf 